\title{
Subjective Well-being and Religiosity: A study of Optimists and Pessimists
}

\author{
Mohd Amin Wani ${ }^{1}$, Prof. Mahmood S. Khan ${ }^{2}$
}

\section{ABSTRACT:}

Pessimist Individuals see difficulty in every opportunity where as Optimists see opportunity in every difficulty. Taking into consideration these characteristics of Optimism and Pessimism, this study was designed to conduct on the samples of the Optimist and Pessimist subjects in order to ascertain the influence of Religiosity on Subjective Well-being. Using Purposive Sampling technique, 50 Optimist and 50 Pessimist Post Graduate students were selected with the help of Life Orientation Test-Revised (LOT-R) developed by Scheier, Carver, \& Bridges, (1994). Religiosity and Subjective Well-being among Optimists and Pessimists were assessed on the basis of scores on Religiosity Scale developed by Deka and Broota, (1985) and Subjective Wellbeing Inventory (SUBI) developed by Sell and Nagpal (1992). Data was analyzed with the help of Simple Linear Regression. The first finding revealed that Religiosity appeared as a significant predictor of Subjective well-being among Optimists. It means that there is a significant positive correlation ' $\mathrm{R}$ ' $=.774$ between Religiosity and Subjective Well-being among Optimists whereas, the second finding also revealed that Religiosity appeared as a significant predictor of Subjective Well-being among Pessimists. This indicates that there is also a significant positive correlation ' $R$ ' = .497 between Religiosity and Subjective Well-being among Pessimists. Since, the Optimists and Pessimists were found in maintaining good Subjective Well-being but the value of ' $\mathrm{R}$ ' in case of Optimists was found to be much higher. So as on the basis of the obtained results , it is discussed that the Optimists look into more favorable side in the face of events and anticipate best possible outcomes in their favor as compared to the Pessimist counterpart. It is suggested that one has to make efforts to be Optimist rather than Pessimist to conquer challenges in their life.

Keywords: Subjective Well-being, Religiosity, Optimists, and Pessimists.

Optimism is a thinking based trait of an individual that can lead to go ahead by preserving a mindset which could be related with one's attaining success in life. Optimists are therefore able to achieve success in most of their pursuits.

${ }^{1}$ Research Scholar, Department of Psychology, Aligarh Muslim University, Aligarh

${ }^{2}$ Professor, Department of Psychology, Aligarh Muslim University, Aligarh 
While Pessimistic people are left behind and have few accomplishments. It is rather infrequently true that a Pessimistic person is also successful, happy, and have fairly good accomplishments. But they often show the tendency of withdrawn low risk taking behaviour and are not always mentally prepared and assertive towards the achievements. They try to succeed but live with a conflicting state of mindset. It is important to mention that an individual doesn't attain success miraculously rather it depends upon several factors which might be reasonably responsible for one's attaining success. Optimism is one such factor. Setbacks and bruises are left behind by an optimistic individual. Failures seem to be hardly possible, if an individual learns and decides to bounce back from such obstacles and prefers to remain undefeated. He strives to strengthen his Optimism and makes his mind to endure every test in life. The expectation of being more successful makes them work harder to achieve their goals. That is why Optimists are more successful at what they do. Choosing to focus on actively finding solutions instead of what is going wrong and with this vision, they are able to conquer and win. The memories of their success drive them forward in difficult times. It is much easier to think of the possibilities, than to wallow in the negative ones. Once the Optimistic mindset is built, an individual will rediscover the God that lives within and his path i.e. Religiosity and will start a life with renewed passion and earnest resolve. In this way, we can imagine how important is to imbibe an Optimistic mindset.

It seemed important to conduct a study after looking at the contribution of Optimism towards an individual's success. And if an individual is Optimist rather than a Pessimist, it is obvious that he may be possessing better Subjective Well-being and may be directed towards the path of God. Scheier and Carver (1993); Scheier, Weintraub, \& Carver, (1986), suggested that optimists report higher SWB because they manage critical life situations better than pessimists do. That is, optimists tend to deal with the source of the stress using a problem-focused coping strategy, whereas pessimists tend to avoid directly confronting the problem itself and use an emotionfocused coping strategy. Optimism is understood to have a strong link with religion (Sethi \& Seligman 1993, Mattis, Fontenot \& Hatcher-Kay 2003).

Optimism, Religiosity, and Subjective Well-being are in combination responsible for the grand success of an individual. So a need aroused to see, Is optimistic mindset rather than a Pessimistic mindset in a real sense a factor contributing to religiosity and Subjective Well-being?

\section{SUBJECTIVE WELL-BEING}

Subjective well-being describes people's evaluations concerning to their lives, including both affective and cognitive dimensions (Diener, Lucas, \& Oishi, 2002). The affective dimension relates one's experiences of positive affect - joy, happiness, and pride where as the negative affect such as sadness, stress, and guilt. The cognitive dimension refers to people's satisfaction in life (Diener, Suh, Lucas, \& Smith, 1999).

Subjective Well-being has been found to be correlated with optimism (Scheier \& Carver, 1985), self-esteem (Wilson, 1967), and control beliefs (Lachman \& Weaver, 1998).

A recent meta-analysis of optimism supported by earlier findings indicate that optimism is positively correlated with life satisfaction, happiness, psychological and physical well-being and negatively correlated with depression and anxiety (Khazen \& Steven). 
The relationship between optimism and subjective well-being seem to vary in adults of different ages, but divergently that cause different forms of optimism. A central tenet of the compensatory theories that account for how overall well-being may remain stable as individuals age is that the importance of divergent domains may shift (for example, the model of Selective Optimization with Compensation: Baltes \& Baltes, 1990).

\section{RELIGIOSITY}

Religiosity refers to a broad set of beliefs and behaviors centering on the sacred (Hood, Hill, \& Spilka, 2009). Religiosity, in its broadest sense, is a comprehensive Sociological term used to refer to the numerous aspects of religious activity, dedication, and belief. Another term that would work equally well, though less used, is religiousness. In its narrowest sense, religiosity deals with how religious a person is, and less with how a person is religious.

Park \& Folkman (1997) viewed that holding spiritual or religious beliefs can increase people's likelihood of finding positive meaning in life. Positive emotions not only to feel good but balancing positive and negative emotions can contribute to one's perception of life satisfaction (Hayes \& Weathington, 2007).

A growing body of research suggests that greater religious involvement is associated with higher levels of subjective well-being (Ellison \& Henderson, 2011). For example, relative to their less religious counterparts, more religious individuals are happier (Myers, 2000), less distressed and anxious (Ellison \& Levin, 1998), and more satisfied in life (Hackney \& Sanders, 2003). Beyond cross-sectional associations, religiosity predicts improvements of well-being over periods of months and even years, such as alleviating depressive symptoms (McIntosh, Poulin, Silver, \& Holman, 2011), fostering greater optimism (Ai, Peterson, Bolling, \& Koenig, 2002), and increasing life satisfaction (Koenig \& Vaillant, 2009).

\section{OPTIMISM AND PESSIMISM}

Carver \& Scheier (1990) "Optimists, by definition, are people with favorable expectations about the future. Such expectations should make success on a given problem seem more likely and should thereby promote continued problem-solving efforts, resulting in better outcomes."

Scheier, Carver and Bridges, (2001), tell us about the 'optimistic advantage' which is due to differences in the manner in which optimists and pessimists cope with the difficulties they confront. So as the optimists seem intent on facing problems head-on, taking active and constructive steps to solve their problems; pessimists are more likely to postpone their effort to attain their goals.

Optimists believe that positive events are more stable and frequent than negative ones. They think that they can avoid problems on their own in daily life and prevent them from happening, and in result of it they are prepared to cope with stressful situations more successfully than pessimists. (Aspinwall, et al., 2001, Peterson and De Avila, 1995)

Optimism is understood to have a strong link with religion (Sethi \& Seligman 1993, Mattis, Fontenot \& Hatcher-Kay 2003). Tiger (1979) argues that religion developed as a response to fulfilling a biological need for people to be optimistic with religious thought mirroring that of 
optimism in its certainty. To have faith in religion there requires a certain amount of optimism to maintain the belief that a superior being will protect and save them, reserving a special place in the afterlife for them.

Individuals with more positive self-illusions, including unrealistically positive self-perceptions or overly optimistic views of the future, not only have higher SWB but other qualities such as caring for others and the ability to engage in productive work (Taylor \& Brown, 1994).

An individual's disposition, including optimism, is an important predictor of well-being, so too is the social aspect of one's life (Finch \& Graziano, 2001).

\section{AIM OF THE STUDY}

The present study is designed to determine the influence of Religiosity on Subjective Well-being among Optimists and Pessimists. In the light of these objectives the following Research Questions are raised to be investigated.

- Is there any influence of Religiosity on Subjective Well-being among Optimists?

- Is there any influence of Religiosity on Subjective Well-being among Pessimists?

\section{METHODOLOGY}

\section{Sample}

The participants of this study were selected by means of purposive sampling technique from the Post Graduate classes of different department of A.M.U. Optimists and Pessimists were identified by Life Orientation Test- Revised (LOT-R) developed by Scheier, Carver, and Bridges (1994). The total sample consisted of 100 participants with equal number of Optimists $(n=50)$ and Pessimists $(\mathrm{n}=50)$

\section{Tools}

\section{Religiosity scale}

To measure the Religiosity among Optimists and Pessimists, The Religiosity scale developed by Deka and Broota (1985) was used. The scale consisted of 44 items, out of which 25 are positively keyed and 19 are negatively keyed. The presence of both positively and negatively worded items included in the test was to avoid the tendency of the respondent to develop a response set that might occur, were the items only positive or only negative. In this way the adequacy of the response given by the participants could be established. The reliability coefficient for the religiosity scale was 0.96 for an adult sample of subjects.

Subjective Well-being Inventory (SUBI)

Subjective Well-being Inventory developed by Sell and Nagpal (1992) was used. It is a self reported questionnaire consisting of 40 items designed to measure an individual's mental status regarding overall feeling about life. These 40 items are divided into eleven factorial dimensions 
namely- Positive affect, Expectation-Achievement congruence, confidence in coping, Transcendence, Family group support, Social support, Primary group concern, Inadequate mental mastery, Perceived ill-health, Deficiency in social contacts and General wellbeing negative affect. For positive items, score is 3,2 and 1 respectively and vice-versa for the negative items. The sum of all 40 items gives overall Subjective Wellbeing score. Higher score indicates better Subjective Well Being and vice-versa. The scale has been found to have high inter-rater, interscorer, and test-retest reliability and has proved its validity through many experiments (Grandall, 1976; Huisman. 1981) and was therefore considered appropriate for this study

\section{Question-wise Scoring}

In 19 out of 40 questions (questions 1-15, 21-23 and 28)- Value 3 was given if the respondent has selected the category 1 (very much); Value 2 was given if the respondent has selected the category 2 (to some extent); Value 1 was given to category 3 (not so much). In the remaining 21 questions (questions 16-20, 24-27 and 29-40)- Value 1 was given if the respondent has selected the category 1 (very much); Value 2 was given if the respondent has selected the category 2 (to some extent); Value 3 was given to category 3 (not so much). However, for questions 14, 27 and 29 , if the respondent has selected category 4, value 0 (zero) was given. All the values were added to get the total score. The maximum score on the test is 120 . Higher the score, higher is the Subjective Well Being of a person. The total score can be interpreted summarily in the light of three broad score ranges: 40-60, 61-80 and 81-120 to have an overall picture of the well being status. The mean score on normal adult Indian samples is 90.8 with standard deviation of 9.2.

\section{Life Orientation Test-Revised (LOT-R)}

Life Orientation Test-Revised (LOT-R) developed by Scheier, Carver, and Bridges (1994) was used to identify the Optimists and Pessimists. This Scale is a 10-item measure of Optimism versus Pessimism. Out of which 3 items measure Optimism, 3 items measure Pessimism, and 4 items serve as fillers. It is a 4-point Likert Scale, $0=$ Strongly disagree, $1=$ Disagree, $2=$ Neutral, 3= Agree, and 4= Strongly agree.

LOT-R is a revised version of the original LOT (Scheier \& Carver, 1992). The original LOT had 12 items: 4 worded positively, 4 worded negatively and 4 fillers.

Items 3, 7, and 9 are reverse scored (or scored separately as a Pessimism measure). Items 2, 5, 6, and 8 are fillers and should not be scored.

Scheier, Carver and Bridges report an internal reliability coefficient of .78 for an undergraduate sample.

\section{PROCEDURE}

The participants selected gave their consent to be the part of the present study. They were told about the purpose of the study. After that, LOT-R developed by Scheier, Carver, and Bridges (1994) was administered on 150 participants in order to identify the Optimists and Pessimists. In this way 100 participants were finally identified as Optimists $(n=50)$ and Pessimists $(n=50)$. Religiosity scale and Subjective Well-being Inventory (SUBI) were administered on participants 
to asses Religiosity and subjective Well-being. After collection of the data, Simple Linear Regression was used to analyze the obtained data.

\section{RESULTS AND DISCUSSION}

Table 1: Represents Linear Regression Analysis to indicate relationship between Religiosity and Subjective Well-being of Optimists.

\begin{tabular}{|l|l|l|l|l|}
\hline \multicolumn{3}{|l|}{ Model Summary } \\
\hline Model & R & R Square & $\begin{array}{l}\text { Adjusted } \\
\text { Square }\end{array}$ & $\begin{array}{l}\text { R } \\
\text { Change Statistics } \\
\text { R Square Change }\end{array}$ \\
\hline 1 & .774 & .599 & .590 & .599 \\
\hline \multicolumn{7}{|l}{ a. Predictors: (Constant), Religiosity Optimists } \\
\hline
\end{tabular}

The above table shows Simple Linear Regression analysis of Religiosity, it showed that Religiosity appeared as significant predictor of Subjective Well-being. It was found that Religiosity (Predictor) emerged to influenced significantly the youths' Subjective Well-being (Criterion). This table shows the model summary, which indicates one predictor of the model. The correlation was found to be $\mathrm{R}=.774$. $\mathrm{R}$ Square change mentioned in the above table indicates the actual contribution of predictor variable to the criterion variable. Therefore the original covariance, the magnitude of independent variable which contributed to the dependent variable (Subjective Well-being) came out as $59.9 \%$.

Table 2: Represents the details of Coefficients between Religiosity and Subjective Wellbeing of Optimists.

\begin{tabular}{|c|c|c|c|c|c|c|}
\hline \multicolumn{7}{|c|}{ Coefficients } \\
\hline & & \multirow{2}{*}{\multicolumn{2}{|c|}{$\begin{array}{l}\text { Unstandardized } \\
\text { Coefficients }\end{array}$}} & \multirow{3}{*}{$\begin{array}{l}\text { Standardized } \\
\text { Coefficients } \\
\text { Beta } \\
\end{array}$} & \multirow[b]{3}{*}{$\mathrm{t}$} & \multirow[b]{3}{*}{ Sig. } \\
\hline & & & & & & \\
\hline \multicolumn{2}{|c|}{ Model } & B & Std. Error & & & \\
\hline \multirow[t]{2}{*}{1} & (Constant) & -37.091 & 16.980 & & -2.184 & .034 \\
\hline & $\begin{array}{l}\text { Religiosity } \\
\text { Optimists }\end{array}$ & .697 & .082 & .774 & 8.463 & .000 \\
\hline
\end{tabular}

The above table clearly shows that Religiosity, the predictor variable influences Subjective Wellbeing (Criterion). The Statistical value given in the table was found significant for above mentioned predictor that is Religiosity indicating a relationship between predictor and criterion variable Subjective Well-being.

The value of Partial Correlation is $r=.774$, therefore predictor significantly influenced the degree of Well-being, this finding indicates that Religiosity appeared as a significant factor of Subjective Well-being among Optimists. The table indicates a significant positive correlation exists between Religiosity and Subjective Well-being among Optimists. It means that when 
Religiosity increases Subjective Well-being also increases and when Religiosity decreases Subjective Well-being also decreases.

Research suggests that greater religious involvement is associated with higher levels of subjective well-being (Ellison \& Henderson, 2011). For example, relative to their less religious counterparts, more religious individuals are happier (Myers, 2000), less distressed and anxious (Ellison \& Levin, 1998), and more satisfied in life (Hackney \& Sanders, 2003).

Scheier and Carver, (1985) found that Optimistic individuals are positive about events they face in daily life. In the research carried out regarding this perspective, positive correlations have been found between Optimism and physical/mental well-being.

Subjective well-being has also been found to be correlated with optimism (Scheier \& Carver, 1985), self-esteem (Wilson, 1967), and control beliefs (Lachman \& Weaver, 1998).

Individuals with more positive self-illusions, including unrealistically positive self-perceptions or overly optimistic views of the future, not only have higher SWB but other qualities such as caring for others and the ability to engage in productive work (Taylor \& Brown, 1994).

In conclusion of the findings of above studies, we may say that Optimists are more religious because they have positive outlook on everything in their life and Religiosity is intimately associated with Subjective Well-being. This indicates that if an individual is Optimistic and highly religious, this Religiosity and Optimism can influence his Subjective Well-being in a positive manner.

Table 3: Represents Linear Regression Analysis to find out relationship between Religiosity and Subjective Well-being of Pessimists.

\begin{tabular}{|l|l|l|l|l|}
\hline \multicolumn{3}{|l|}{ Model Summary } \\
\hline Model & $\mathrm{R}$ & R Square & $\begin{array}{l}\text { Adjusted } \\
\text { Square }\end{array}$ & $\begin{array}{l}\text { Change Statistics } \\
\text { R Square Change }\end{array}$ \\
\hline 1 & $.497^{\mathrm{a}}$ & .247 & .231 & .247 \\
\hline \multicolumn{7}{|l}{ a. Predictors: (Constant), Religiosity Pessimists } \\
\hline
\end{tabular}

Simple Linear Regression analysis of Religiosity as showed in the above table reveals that Religiosity appeared as significant predictor of Subjective Well-being. It was found that Religiosity (Predictor) was upheld as significant predictor of Subjective Well-being (Criterion). This table shows the model summary, which indicates one predictor of the model. The correlation was found to be $\mathrm{R}=.497$. $\mathrm{R}$ Square change mentioned in the above table indicates the actual contribution of predictor variable to the criterion variable. Therefore the original covariance, the magnitude of independent variable which contributed to the dependent variable (Subjective Well-being) came out as $24.7 \%$. 
Table 4: Represents the details of Coefficients between Religiosity and Subjective Wellbeing of Optimists.

\begin{tabular}{|c|c|c|c|c|c|c|}
\hline \multicolumn{7}{|c|}{ Coefficients } \\
\hline & & \multicolumn{2}{|c|}{$\begin{array}{l}\text { Unstandardized } \\
\text { Coefficients }\end{array}$} & \multirow{2}{*}{\begin{tabular}{|l} 
Standardized \\
Coefficients \\
Beta \\
\end{tabular}} & \multirow[b]{2}{*}{$\mathrm{T}$} & \multirow[b]{2}{*}{ Sig. } \\
\hline \multicolumn{2}{|c|}{ Model } & B & Std. Error & & & \\
\hline \multirow[t]{2}{*}{1} & (Constant) & -66.418 & 43.117 & & -1.540 & .130 \\
\hline & $\begin{array}{l}\text { Religiosity } \\
\text { Pessimists }\end{array}$ & .843 & .213 & .497 & 3.967 & .000 \\
\hline \multicolumn{7}{|c|}{ a. Dependent Variable: Subjective Well-being Pessimists } \\
\hline
\end{tabular}

The above table clearly shows that Religiosity, (the predictor variable) influenced the Subjective Well-being (Criterion). The Statistical value given in the table was found to be $t=3.967$ which is significant for above mentioned predictor that is Religiosity, indicating relationship between predictor and criterion variable Subjective Well-being.

The value of Partial Correlation is $r=.497$, therefore predictor variable significantly influenced the degree of Subjective Well-being. The obtained finding indicates that Religiosity appeared as potential factor of Subjective Well-being among Pessimists also. It may be seen in the table that a significant positive correlation exists between Religiosity and Subjective Well-being among the Pessimists too. It means that when Religiosity increases Subjective Well-being also increases and when Religiosity decreases Subjective Well-being also decreases. Despite the fact that Pessimists have a narrow outlook on every aspect of life, there should be a negative correlation between Religiosity and Subjective well-being. This finding revealed relatively weak contribution of the independent variable towards dependent variable in the sample of Pessimists as compared to Optimists.

Several studies have confirmed that optimists tend to use coping strategies that focalize on the problem more frequently while compared with pessimists. (Scheier, et al., 1986, Rasmussen, et al., 2006, Wrosch \& Scheier, 2003).

Scheier and Carver reported that optimists and pessimists have different patterns of behavior and expectations in relation to the achievement of goals. Since optimists tend to believe strongly that their actions will lead to a positive outcome, they persist in those actions and achieve their goals with more confidence often than pessimists, who usually show some fear of failure and more often withdrawn tendency, so put less efforts and disengage from the goals they have set. Scheier and Carver (1993; Scheier, Weintraub, \& Carver, 1986) suggested that optimists report higher SWB because they manage critical life situations better than pessimists do.

In the light of the above studies, we may say that Pessimists are relatively not better than Optimists in any respect. Pessimists face difficulty in solving problems. They have fickle goals in their lives with the tendency of reluctance. So they often fail to cope well in face of daily 
stressors, they can't adapt to Psychological illness and finally they are not better in terms of Subjective Well-being. But, if we consider the second finding of the study, a significant positive correlation between Religiosity and Subjective Well-being among Pessimists was found. One study could partially support this finding e.g. Robinson- Whelen, Kim, MacCallum and KiecoltGlaser (1997) reported that pessimism, but not optimism, was able to predict health and wellbeing. This finding could also be possible because an individual either Optimistic or Pessimistic may have a positive outlook in the name of religion, a pessimist may also be Godfearing and may also have a deep faith in mortality which impels him towards attending Religious activities. Therefore a Pessimist can be equal to an optimist so far the faith in Religiosity is concerned. As the Subjective Well-being of Optimists is better and Pessimists are not far behind from Optimists as observed in the study in terms of Religion, then Pessimists might show better levels of Subjective Well-being. Since the students of A.M.U served as subjects in this study and the environment of university campus is religiously conducive for offering prayer. Therefore the Well-being of Pessimists who were religious appeared to be almost similar to that of Optimists. So it is needed to conduct study in different social setting and environment. If religious practices are truly observed in any environment, might change the Pessimistic trait of the individuals as per obtained finding of the study.

\section{REFERENCES.}

1. Ai, A. L., Peterson, C., Bolling, S. F., \& Koenig, H. (2002). Private prayer and optimism in middle-aged and older patients awaiting cardiac surgery. The Gerontologist, 42(1), 7081.

2. Aspinwall, L. G., Richter, L., Hoffman, R. R. Understanding how optimism works: an examination of optimists' adaptive moderation of belief and behaviour. In: Optimism and pessimism. Chang EC, Ed. Washington: American Psychological Association 2001; pp. 217-38.

3. Baltes, P. B., \& Baltes, M. M. (1990). Psychological perspectives on successful aging: The model of selective optimization with compensation. In P. B. Baltes \& M. M. Baltes (Eds.), Successful aging: Perspectives from the behavioral sciences (pp. 1-34). New York: Cambridge University Press.

4. Barrett, C. E., \& Roesch, S. C. (2009). Evaluating the relationship between the five factor model of personality and religious orientation. Journal of Psychology and Christianity, 28(3), 195-199.

5. Carver, C. S., \& Scheier, M. F. (1990). Principles of self-regulation: Action and emotion. In E. T. Higgins \& R. M. Sorrentino (Eds.), Handbook of motivation and cognition (Vol. 2, pp. 3-52). New York: Guilford Press.

6. Carver, C. S., Scheier, M. F., \& Weintraub, J. K. (1989), Assessing coping strategies: A theoretically based approach, Journal of personality and social psychology, 56(2), 267283. 
7. Deka, N., Broota, K. D. Moral Judgement and Religiosity: A comparative study of the majority and minority religious groups in India. University of Delhi, India: Unpublished Doctoral dissertation; 1985.

8. Diener, E., Lucas, R. E., \& Oishi, S. (2002). Subjective well-being: The science of happiness and life satisfaction. In C. R. Snyder \& S. J. Lopez (Eds.), Handbook of positive psychology (pp. 63-73). New York, NY: Oxford University Press.

9. Ellison, C. G., \& Henderson, A. K. (2011). Religion and mental health: Through the lens of the stress process. In A. J. Blasi (Ed.), Toward a sociological theory of religion and health (pp. 11-44). Leiden, Netherlands: Brill.

10. Ellison, C. G., \& Levin, J. S. (1998). The religion-health connection: Evidence, theory, and future directions. Health Education and Behavior, 25(6), 700-720.

11. Finch, J. F., \& Graziano, W. G. (2001). Predicting depression from temperament, personality, and patterns of social relations. Journal of Personality, 69, 27-52.

12. Hackney, C. H., \& Sanders, G. S. (2003). Religiosity and mental health: A meta-analysis of recent studies. Journal for the Scientific Study of Religion, 42(1), 43-55

13. Hayes, C. T., \& Weathington, B. L. (2007), Optimism, stress, life satisfaction, and job burnout in restaurant managers, Journal of psychology, 141(6), 565-579.

14. Hill, P. C., \& Pargament, K. I. (2003). Advances in the conceptualization and measurement of religion and spirituality: Implications for physical and mental health research. American Psychologist, 58(1), 64-74.

15. Hood, R. W., Jr., Hill, P. C., \& Spilka, B. (2009). The psychology of religion: An empirical approach (4th ed.). New York, NY: Guilford Press.

16. Khazon, Steven. "Great expectations: A meta-analytic examination of optimism and hope." Personality and Individual Differences (): 821-827. Print.

17. Koenig, L. B., \& Vaillant, G. E. (2009). A prospective study of church attendance and health over the lifespan. Health Psychology, 28(1), 117-124.

18. Lachman, M. E., \& Weaver, S. L. (1998). The sense of control as a moderator of social class differences in health and well-being. Journal of Personality and Social Psychology, 74, 763-773.

19. Mattis, J. S., Fontenot, D. L., \& Hatcher-Kay, C. A., (2003), Religiosity, racism and dispositional optimism among African Americans, Personality and individual differences, 34(6), 1025.

20. McIntosh, D. N., Poulin, M. J., Silver, R. C., \& Holman, E. A. (2011). The distinct roles of spirituality and religiosity in physical and mental health after collective trauma: A national longitudinal study of responses to the 9/11 attacks. Journal of Behavioral Medicine, 34(6), 497-507.

21. Myers, D. G. (2000). The funds, friends, and faith of happy people. American Psychologist, 55(1), 56-67.

22. Park, C. L., \& Folkman, S., (1997), Meaning in the context of stress and coping, Review of general psychology, 1(2), 115-144. doi:10.1037/1089-2680.1.2.115. 
23. Peterson, C., De Avila, M. E. Optimistic explanatory style and the perception of health problems. J Clin Psychol 1995; 51(1): 128-32.

24. Rasmussen, H. N., Wrosch, C., Scheier, M. F., Carver, C. S.(2006). Self-regulation processes and health: the importance of optimism and goal adjustment. J Personal Disord; 74(6): 1721-48.

25. Scheier, M. F., Carver, C. S. (1985). Optimism, coping, and health: assessment and implications of generalized outcome expectancies. Health Psychol, 4(3): 219-47.

26. Scheier, M. F., \& Carver, C. S. (1993). On the power of positive thinking: The benefits of being optimistic. Current Directions in Psychological Science, 2, 26-30.

27. Scheier, M. F., Carver, C. S., \& Bridges, M. W. (2001). Optimism, pessimism, and psychological well-being. In E. C. Chang (Ed.), Optimism and pessimism: Implications for theory, research, and practice. (pp. 189-216). Washington D.C.: American Psychological Association.

28. Scheier, M. F., Carver, C. S., \& Bridges, M. W. (1994). Distinguishing optimism from neuroticism (and trait anxiety, self mastery, and self-esteem): A re-evaluation of the Life Orientation Test. Journal of Personality and Social Psychology, 67, 1063-1078

29. Scheier, M. F., Weintraub, J., \& Carver, C. S., (1986), Coping with stress: Divergent strategies of optimists and pessimists, Journal Of Personality \& Social Psychology, 51(6), 1257-1264.

30. Sell, H., \& Nagpal, R. (1992). The Subjective Well-Being Inventory (SUBI). Regional Health Paper, SEARO 24. World Health Organization (WHO); Geneva. Accessed from, http://whqlibdoc.who.int/searo/rhp/SEARO_RHP_24.pdf.

31. Sethi, S., \& Seligman, M. E. P. (1993). Optimism and fundamentalism, Psychological Science, 4, 256-259.

32. Taylor, S. E., \& Brown, J. D. (1994). Positive illusions and well-being revisited: Separating fact from fiction. Psychological Bulletin, 116, 21-27.

33. Tiger, L. (1979). Optimism: The biology of hope, New York, Simon \& Schuster.

34. Wilson, W. (1967). Correlates of avowed happiness. Psychological Bulletin, 67, 294-306.

35. Wrosch, C., Scheier, M. F. (2003). Personality and quality of life: the importance of optimism and goal adjustment. Qual Life Res; 12(1): 59-72. 